\title{
SPECTRUM OF COMPLICATION OF CARDIAC DISEASE IN MATERNITY IN A LOW RESOURCE SETTING AND COMPARISON WITH CARPREG SCORING
}

\author{
Uma Dharmalingam¹, Prasannalakshmi Subramanian², Gomathi Velusamy³ \\ ${ }^{1}$ Associate Professor, Department of Obstetrics and Gynaecology, KAPV Government Medical College, Trichy. \\ ${ }^{2}$ Assistant Professor, Department of Obstetrics and Gynaecology, KAPV Government Medical College, Trichy. \\ 3Junior Resident, Department of Obstetrics and Gynaecology, KAPV Government Medical College, Trichy.
}

\section{ABSTRACT}

\section{BACKGROUND}

Nowadays heart disease is an important risk factor for maternal mortality. Aims of this study are to know the incidence of heart disease among pregnant women during the study period; to study the various aetiological types of heart disease and also classify the heart disease based on the WHO risk classification; to know the factors affecting maternal and foetal outcome in heart disease complicating pregnancy and also predict the patient outcome on CARPREG scoring system.

\section{MATERIALS AND METHODS}

The present study was done at KAPV Govt. Medical College, Trichy. Total number of deliveries during the study period was 4833. In the present study, 50 patients with cardiac disease complicating pregnancy were studied over a period of 6 months from June 2016 to November 2016.

\section{RESULTS}

In this study, most common incidence was rheumatic heart disease. All cardiac diseases were compared with CARPREG scoring. Score more than 1 has a high mortality rate.

\section{CONCLUSION}

Early referral and diagnosis of heart disease help in critical care and prevent maternal complications.

\section{KEYWORDS}

NYHA, CARPREG, Heart Disease.

HOW TO CITE THIS ARTICLE: Dharmalingam U, Subramanian P, Velusamy G. Spectrum of complication of cardiac disease in maternity in a low resource setting and comparison with CARPREG scoring. J. Evolution Med. Dent. Sci. 2017;6(17):1344-1347, DOI: $10.14260 / \mathrm{Jemds} / 2017 / 292$

\section{BACKGROUND}

In developing countries, cardiac disease complicating pregnancy is an important indirect cause of maternal mortality. In our study, aims were to know about the complication, prevalence, aetiology, types of lesion, maternal \& foetal outcome in heart disease complicating pregnancy. In low resource setting like primary health centre and urban health centres, many cases were referred to our tertiary centre for suspected heart disease and here cardiac evaluation was done to confirm the heart disease. Prevalence of heart disease in this study period was $1.03 \%$. Rheumatic heart disease was the commonest, followed by congenital heart disease. In our study, among RHD, mitral stenosis was the commonest. Maternal death in this study occurred in the cases of previously undiagnosed heart disease who came to the hospital for the first time in labour. Many cases were diagnosed for first time only after occurrence of complications. These can be prevented by early referral to higher centre \& simple auscultation of cardiovascular system in every antenatal check-up in health centre.

The marked anatomical \& functional changes during pregnancy in cardiovascular system cause profound effect on

Financial or Other, Competing Interest: None.

Submission 29-12-2016, Peer Review 12-02-2017,

Acceptance 18-02-2017, Published 27-02-2017.

Corresponding Author:

Dr. Gomathi Velusamy,

\#1/171, Kalampalayam,

Pongupalayam (P.O.) Tiruppur-641666.

E-mail: goms4klm@gmail.com

DOI: $10.14260 /$ jemds $/ 2017 / 292$

\section{(c) $($ () $\ominus$} underlying heart disease. ${ }^{1}$ About $50 \%$ of cardiac abnormalities are first diagnosed during routine antenatal examination or because of symptoms brought on by the physiological changes of pregnancy. But detection of heart disease in early stages is still a problem. Hence, undiagnosed heart disease in pregnant women is a challenge to the obstetrician, cardiologist and neonatologist. At present, $1.03 \%$ of all pregnancies are complicated by heart disease, ${ }^{2}$ among which rheumatic heart disease is the commonest heart disease in the pregnancy and half of which are diagnosed at a later period. Surgical correction of congenital heart disease helps to carry out the pregnancy till term without any complication. NYHA classification of the pregnant women with heart disease helps in predicting the outcome of the patient. Preeclampsia, caesarean section associated with heart disease are important added risk factors for mortality. ${ }^{3}$

Pregnant women with cardiac disease are categorised by WHO (World Health Organisation) risk classification based on their cardiac lesions. Also compared with CARPREG scoring and predict the outcome.

Heart disease and pregnancy may both affect each other adversely. Multidisciplinary care of obstetrician, cardiologist and anaesthetist helps in preventing complications. Cardiac disease in a mother added complication not only to her but also to her family members. Regular followup is needed antenatally and postnatally to avoid complications.

\section{Aims and Objectives}

1. To study the incidence of heart disease among pregnant women during the study period. 
2. To study the various aetiological types of heart disease and also classify the heart disease based on the WHO risk classification.

3. To know the factors affecting maternal and foetal outcome in heart disease complicating pregnancy. Also predict the patient outcome on CARPREG scoring system.

\section{MATERIALS AND METHODS}

The present study was done at KAPV Govt. Medical College, Trichy. It is a referral hospital covering large obstetric population in Trichy District and also complicated cases referred from Pudukkottai, Karur \& Perambalur district. Total number of deliveries during the study period was 4833 . In the present study, 50 patients with cardiac disease complicating pregnancy were studied over a period of 6 months from June 2016 to November 2016. These included referral cases from all PHC centres, booked cases in the antenatal OPD and unbooked emergency cases. The women were divided into three groups - Rheumatic heart disease, congenital heart disease and miscellaneous. All the groups were subdivided into surgically corrected group and noncorrected group. Also, classified the group based on WHO risk classification. Compared the outcome of the patient with CARPREG scoring. The above groups were studied for maternal morbidity, maternal mortality, preterm birth, intrauterine growth restriction and intrauterine foetal death. History of occurrence of rheumatic fever in childhood or adolescence was elicited. A detailed medical history and obstetric history were taken. Functional class of the patient before the present pregnancy was determined. Data on the present pregnancy was collected. A detailed clinical examination was performed. Obstetric examination was done to note the height of the uterus and to detect any intrauterine growth restriction. A search was made for symptoms and signs of infections anywhere in the body, such as chest, urinary tract and cervicovaginal infections and if found, these were treated aggressively. Patients were advised on the importance of taking adequate rest. They were given Iron and Folate supplements. Intensive care during labour and postpartum period was given. Early referral from PHC helps in effective management in tertiary care.

\section{Management}

For all heart disease complicating pregnancy patients, all routine investigations like haemoglobin, blood group and $\mathrm{Rh}$ type, blood sugar, VDRL, urinalysis and urine culture was done in all the patients. Electrocardiography and Echocardiography were done in all the patients and the clinical diagnosis was confirmed.

We confirmed their cardiac lesion \& categorised into mild or severe and also classified as per NYHA classification. Class I \& II group cases were admitted in hospital only at third trimester and stayed in hospital till two weeks post-delivery. Based on their symptoms, patients in class III and IV were admitted in the second trimester and remained in the hospital until three weeks post-delivery. Digoxin and diuretics were used in heart failure cases. ${ }^{4}$ Arrhythmia was treated with drugs alone. Complications were treated by the cardiologist. Fluid overload was avoided. We gave adequate sedation for postop cases. Patients were classified based on CARPREG scoring. Prior cardiac events such as heart failure, transient ischaemic attack, stroke before pregnancy, arrhythmia were elicited and also noted as per NYHA classification for any left heart obstruction, ejection fraction. Based on these findings classified CARPREG scoring system; even if the score is 0 the risk of heart disease pregnancy outcome was $5 \%$; if score is 1 the risk of pregnancy outcome was $27 \%$; if score is $>1$ score the risk of pregnancy outcome was $75 \%$. Infective endocarditis prophylaxis was given for all heart disease patients (Inj. Ampicillin 2 g IV b.d. \& Inj. Gentamycin 80 mg IV b.d.). 5

\section{RESULTS}

\begin{tabular}{|c|c|c|}
\hline Age Group & No. & Percentage \\
\hline$<20$ & 1 & $2 \%$ \\
\hline $20-25$ & 22 & $44 \%$ \\
\hline $26-30$ & 14 & $28 \%$ \\
\hline $31-35$ & 11 & $22 \%$ \\
\hline$>35$ & 2 & $4 \%$ \\
\hline \multicolumn{2}{|c|}{ Table 1. Age group Distribution } \\
\hline
\end{tabular}

AGE GROUP DISTRIBUTION

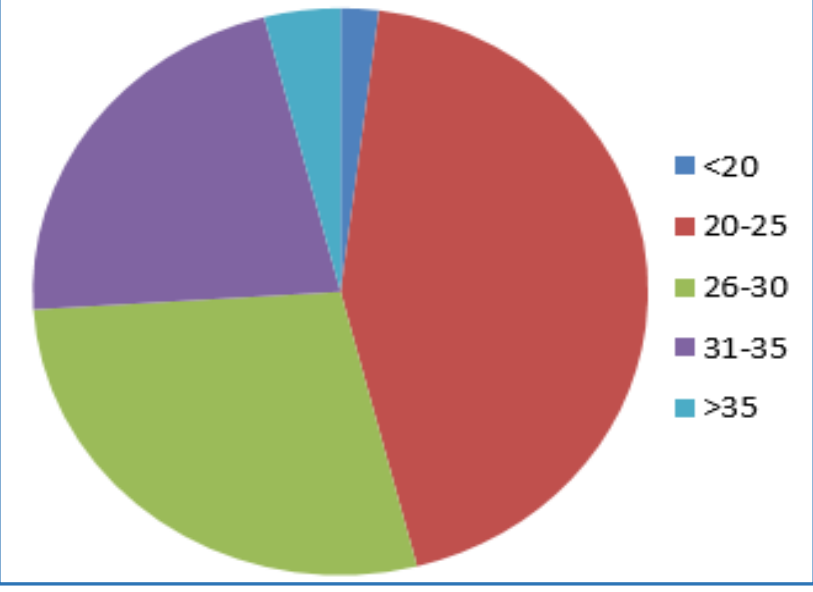

The most common age group where heart disease incidence was common was 20-25 years. With increasing age there was decreasing incidence of heart disease.

\begin{tabular}{|c|c|c|}
\hline Type of Heart Disease & No. & $\mathbf{\%}$ \\
\hline Rheumatic Heart Disease & 25 & $50 \%$ \\
\hline ASD & 6 & $12 \%$ \\
\hline VSD & 2 & $4 \%$ \\
\hline MVP & 7 & $14 \%$ \\
\hline Valve Replacement & 3 & $6 \%$ \\
\hline Primary PHT & 1 & $2 \%$ \\
\hline Others & 6 & $12 \%$ \\
\hline Table 2. Aetiology
\end{tabular}

The most common heart disease is rheumatic heart disease. Among congenital heart disease, ASD was most common one. In other cases, mitral valve prolapse, ventricular premature complex left bundle branch are included.

\begin{tabular}{|c|c|}
\hline Mode of Delivery & No. of Deliveries \\
\hline Labour Naturalis & 19 \\
\hline Outlet Forceps & 2 \\
\hline Emergency LSCS & 16 \\
\hline Elective LSCS & 8 \\
\hline Spontaneous Expulsion & 2 \\
\hline Abortion & 3 \\
\hline \multicolumn{2}{|c|}{ Table 3. Maternal Outcome } \\
\hline
\end{tabular}


Due to intensive care, most common maternal outcome was caesarean section.

\begin{tabular}{|c|c|}
\hline Pregnancy Code & No. \\
\hline Primi & 18 \\
\hline G2 & 19 \\
\hline Multigravida & 13 \\
\hline Table 4 \\
\hline \multicolumn{2}{|c|}{}
\end{tabular}

There was not much discrepancy between primi or multigravida.

\begin{tabular}{|c|c|}
\hline Foetal Outcome & No \\
\hline Term & 40 \\
\hline Preterm & 3 \\
\hline IUGR & 2 \\
\hline IUD & 2 \\
\hline Abortion & 3 \\
\hline Table 5. Foetal Outcome \\
\hline
\end{tabular}

\begin{tabular}{|c|c|}
\hline Causes & No. \\
\hline RHD (Severe Mitral Stenosis) & 1 \\
\hline LBBB & 1 \\
\hline Cardiomyopathy & 1 \\
\hline Table 6. Maternal Death \\
\hline \multicolumn{2}{|c}{} \\
\hline
\end{tabular}

There were 3 maternal deaths in our study. The causes are severe mitral stenosis, LBBB \& cardiomyopathy.

\begin{tabular}{|c|c|c|}
\hline Type & Uncorrected & Corrected \\
\hline ASD & 4 & 2 \\
\hline VSD & 1 & 1 \\
\hline \multicolumn{2}{|c|}{ Table 7. Congenital Heart Disease } \\
\hline
\end{tabular}

Among congenital heart disease, ASD was the most common one.

\begin{tabular}{|c|c|}
\hline Complications \& Comorbidities & No. \\
\hline Pulmonary Oedema & 4 \\
\hline Anaemia & 5 \\
\hline Preeclampsia & 4 \\
\hline Others & 5 \\
\hline Table 8. Maternal Morbidity \\
\hline
\end{tabular}

The most common complication in heart disease is pulmonary oedema. The associated risk factors like anaemia, preeclampsia increase the complications.

\begin{tabular}{|c|c|}
\hline Isolated Mitral Stenosis & 2 \\
\hline Mitral Regurgitation & 3 \\
\hline MS with MR & 12 \\
\hline MS + MR + AR & 2 \\
\hline RHD + Pulmonary Hypertension & 5 \\
\hline MR + TR & 2 \\
\hline Table 9. Rheumatic Heart Disease type \\
\hline
\end{tabular}

Among rheumatic heart disease, mitral stenosis with mitral regurgitation was most common.

\begin{tabular}{|c|c|}
\hline NYHA Class & No. \\
\hline I & 26 \\
\hline II & 15 \\
\hline III & 5 \\
\hline IV & 4 \\
\hline \multicolumn{2}{|c|}{ Table 10. NYHA Classification } \\
\hline
\end{tabular}

Four heart disease cases in NYHA class IV resulted in mortality.

\begin{tabular}{|c|c|}
\hline Score & No. \\
\hline 0 (Risk 5\%) & 32 \\
\hline 1 (Risk 27\%) & 13 \\
\hline$>1(75 \%$ Risk) & 5 \\
\hline Table 11. CARPREG Risk Scoring \\
\hline
\end{tabular}

Among 5 cases in CARPREG score $>1$, three cases ended in maternal death.

\begin{tabular}{|l|c|}
\hline \multicolumn{1}{|c|}{ WHO Classification } & No. \\
\hline 1- Risk no Higher than General Population & 13 \\
\hline $\begin{array}{l}\text { 2- Small Increase in risk of Maternal Mortality \& } \\
\text { Morbidity }\end{array}$ & 31 \\
\hline $\begin{array}{l}\text { 3- Significantly Increased Risk of Maternal Mortality } \\
\text { or Expert Cardiac \& Obstetric Care required }\end{array}$ & 3 \\
\hline $\begin{array}{l}\text { 4- Very High Risk of Maternal Mortality or Severe } \\
\text { Morbidity; Pregnancy Contraindicated \& Termination } \\
\text { Discussed }\end{array}$ & 3 \\
\hline
\end{tabular}

\section{DISCUSSION}

Prevalence of heart disease varies from 0.2 to $0.4 \%$ in various studies. In the present study, the prevalence was $1.03 \%$. Majority of the cases belong to the age group of 20 to 25 years of age. Most common type of heart disease was rheumatic heart disease. Among RHD, combination of mitral stenosis with mitral regurgitation was most common. Congenital heart disease (ASD + VSD) was second most common. ${ }^{6}$ Half of the cases were surgically corrected during childhood period.

Majority of heart disease patients were in the NYHA class I \& II. ${ }^{7}$ In our study, maternal mortality was $6 \%$. The cause of maternal death was LBBB, cardiomyopathy, severe mitral stenosis. Late referral and late detection of heart disease was one of the factor contributing for maternal mortality. In this study, foetal outcome was not much affected by maternal heart disease.

CARPREG scoring was assigned to all patients. 5 cases were with risk score more than one point had risk outcome of more than $75 \%$. Among 5 cases 3 ended with maternal death. Maternal death occurred in the case of LBBB, cardiomyopathy, severe mitral stenosis. Almost all 3 maternal cases were diagnosed late in pregnancy \& referred here at critical time. Thus, early diagnosis helps in prevention of maternal complication. Patients were also classified based on WHO risk classification. 13 patients were in WHO1 classification. 31 cases were in WHO2 classification. Most of the cases are rheumatic valvular heart diseases.

\section{CONCLUSION}

In the present study, the incidence of pregnancy complicated by heart disease was $1.03 \%$. Rheumatic heart disease was the commonest aetiological factor, followed by congenital heart 
disease. Mitral stenosis was most common among the Rheumatic heart disease group and atrial septal defect among the congenital heart disease group. NYHA classes I and II had better prognosis than class III and IV. Maternal mortality was $6 \%$. We conclude that pregnancy outcome is good in booked cases with regular check-up by the obstetrician and the cardiologist, in surgically corrected cases and those with NYHA class I and II. Hence, multidisciplinary management by obstetrician, cardiologist, anaesthetist and neonatologist will go a long way in ensuring a good prognosis among the pregnant patients with heart disease. Early diagnosis of heart diagnosis results in proper management \& intensive care during labour time \& puerperal period. Thus, helps in preventing complications. CARPREG scoring also helps in predicting the outcome of heart disease complicating pregnancy.

\section{REFERENCES}

[1] Uebing A, Steer PJ, Yentis SM, et al. Pregnancy and congenital heart disease. British Medical journal 2006;332(7538):401-6.
[2] Weiss BM, Segesser VLK, Alon E, et al. Outcome of cardiovascular surgery \& pregnancy: a systemic review of the period 1984-1996. American Journal of Obstetrics and Gynaecology 1998;179(6):1643-53.

[3] Mosca L, Benjamin EJ, Berra K, et al. Effectiveness-based guidelines for the prevention of cardiovascular disease in women-2011. American heart association. Circulation 2011;123:1243-62.

[4] Nitsche JF, Philips SD, Rose CH, et al. Pregnancy and delivery in patients with Fontan circulation: a case report and review of obstetric management. Obstet Gynecol Surv 2009;64(9):607-14.

[5] Wilson W, Taubrt KA, Gewitz M, et al. Prevention of infective endocarditis. Circulation 2007;116:1736-54.

[6] Gei AF, Hankins GD. Cardiac disease and pregnancy. Obstet Gynaecol Clin North Am 2001;28(3):465-512.

[7] Subbaiah M, Sharma V, Kumar S, et al. Heart disease in pregnancy: cardiac and obstetrics outcomes. Arch Gynaecol Obstet 2013;288(1):23-7.

[8] Sawhey H, Aggarwal N, Suri V, et al. Maternal \& perinatal outcome in rheumatic heart disease. Int J Gynaecol Obstet 2003;80(1):9-14. 